\title{
BIOCHEMICAL ALTERATIONS IN POSTMENOPAUSAL WOMEN HAVING OSTEOPOROTIC RISK
}

\author{
PREETI SHARMA ${ }^{*}$, PRADEEP KUMAR ${ }^{1}$, RACHNA SHARMA², GAURAV GUPTA ${ }^{1}$
}

${ }^{1}$ Department of Biochemistry, Santosh Medical College \& Hospital, Santosh University, Ghaziabad, Uttar Pradesh, India. ${ }^{2}$ Department of Biochemistry, TSM Medical College \& Hospital, Lucknow, Uttar Pradesh, India. Email: prcdri2003@yahoo.co.in

Received: 21 September 2016, Revised and Accepted: 28 October 2016

ABSTRACT

Objective: Osteoporosis is the most common disease worldwide; nutritional factors may play a significant role in the progression of the disease. The aim of this study was to assess the various biochemical parameters in the postmenopausal women with osteoporosis or osteopenia.

Methods: In this hospital-based study, total 70 postmenopausal women, 45-80 years of age group, were studied. They were categorized into two groups as Case I and Case II on the basis of diagnosis of osteoporosis and osteopenia, respectively. The bone mineral density using T-score was estimated for diagnosis of osteoporosis or osteopenia. Bone mineral markers, i.e., total calcium and ionized calcium (CAI) were estimated by colorimetric method. Serum phosphate was estimated by direct method, and alkaline phosphatase (ALP) was measured by kinetic method. Biochemical parameters, i.e., urea, were estimated by diacetyl monoxime method. Serum albumin and serum creatinine were measured by bromocresol green method and Jaffe's method, respectively. Serum uric acid and magnesium were estimated by colorimetric method.

Results: Total calcium and CAI were significant $(<0.05)$ between the groups. The levels of serum phosphate and ALP were higher in osteoporotic group, but the results were not significant between the groups. Serum urea and serum albumin were comparatively higher and lower in osteoporotic group, respectively, but the findings were not significant between the groups. The significant results of serum creatinine, serum uric acid, and serum magnesium were obtained while comparing between osteoporotic patients and osteopenia patients. The levels were higher in osteoporosis group. There was a negative association of ALP with serum calcium and negative association with serum phosphate and uric acid.

Conclusion: Biochemical alterations are characterized in osteoporotic as well as osteopenic patients. Monitoring of these parameters may be beneficial while giving the treatment to these patients for the prevention of other life-threatening risks.

Keywords: Osteoporosis, Osteopenia, Alkaline phosphatase, Serum creatinine, Postmenopause.

(C) 2017 The Authors. Published by Innovare Academic Sciences Pvt Ltd. This is an open access article under the CC BY license (http://creativecommons. org/licenses/by/4. 0/) DOI: http://dx.doi.org/10.22159/ajpcr.2017.v10i2.15290

\section{INTRODUCTION}

Osteoporosis is the most frequently occurred disease worldwide and has become a public health problem [1]. Osteoporosis is quite common in women compared to men, especially in the elderly population. Osteoporosis, a metabolic skeletal disease, characterized by the microarchitectural deterioration of bone tissue, leading to increased bone fragility and resulting in increased risk of fracture [2]. It is mainly due to the prime deficiency of calcium, as low dietary intake of calcium leads to risk of fractures in later stages [3], and vitamin D, which plays an important role calcium absorption and osteoclastic activity [4]. Factors such as poor vision, inadequate physical activity, aging, frequent falls, low body weight, hormonal changes, poor health, and personal history of fractures may also be associated with osteoporosis [5]. Estrogen plays a fundamental role in skeletal growth, and bone homeostasis and its deficiency make prominence of osteoporosis in postmenopausal women [6]. Nutritional factors play significant role in the body, may be associated with progression of osteoporosis, so the evaluation of other biochemical markers might be useful for avoiding the other life-threatening diseases. Protein malnutrition predisposes to fall and diminish the soft tissue cover over bone prominence; albumin may be the best predictor in osteoporosis [7]. Alkaline phosphatase (ALP), an enzyme found in liver, bone, kidneys, and placenta, is an indicator of osteoblastic activity [8]. Magnesium, an important cation for various metabolic processes [9], has an existing association with bone loss [10] due to approximately 50-60\% presence of it along with calcium phosphate [11]. Studies have indicated that uric acid, a strong endogenous antioxidant, has shown a controversial association with bone mineral density [12,13]. Patients with renal insufficiency may have reduced bone mineral density due to abnormal concentration of vitamin D and parathyroid hormone, and their bone biopsies show the evidence for increased bone turnover [14]. Studies have reported the association between serum creatinine and skeletal muscle mass due to the presence of creatine phosphate in skeletal muscle, of which creatinine is primary product [15]. Hence, the assessment of various parameters in the progression of osteoporosis may be important to know as they play a significant role in other metabolic activities and prevent the risk of future development of other diseases.

\section{METHODS}

\section{Materials}

This study was carried out at the Department of Biochemistry, Santosh Medical College \& Hospital, Ghaziabad. Total 70 postmenopausal women were studied from November 2015 to July 2016. The bone mineral density status of the study group was evaluated for diagnosis of osteoporosis. Each individual voluntarily participated for being a part of the study, and a written consent was taken from them. The fasting blood sample was collected from every participant.

\section{Exclusion criteria}

Postmenopausal women having diabetes mellitus, hypertension, renal disease, thyroid disease, hepatic disorder, secondary osteoporosis, smokers, and alcoholics were excluded from the study.

\section{Inclusion criteria}

Only postmenopausal women 45-80 years of age without having any previous history of bone disease or fracture were included in the study. 
Methods

Bone mineral density usually reported as T-score and Z-score. The site of examination for measuring T-score and Z-score was at tibia and radius. Patients were categorized in two groups, i.e., Case I and Case II on the basis of T-score. Case I regard as osteoporosis (>-2.5 standard deviation [SD]) while Case II reported as osteopenia ( -1 to $-2.5 \mathrm{SD}$ ), in which bone mineral content is lower than normal but greater than osteoporosis [16]. Various parameters, i.e., total calcium (CaT) (8.5$10.5 \mathrm{mg} / \mathrm{dl}$ ), ionized calcium (CaI) (4.6-5.4 mg/dl), serum inorganic phosphate ( $\mathrm{SPO}_{4}$ ) (1.5-6.8 mg/dl), serum ALP (60-170 IU/l), blood urea $(15-50 \mathrm{mg} / \mathrm{dl})$, serum creatinine $(0.6-1.2 \mathrm{mg} / \mathrm{dl})$, serum albumin $(3.5-$ $5 \mathrm{~g} / \mathrm{dl}$ ), serum magnesium (1.9-2.5 mg/dl), and serum uric acid (2.4$5.7 \mathrm{mg} / \mathrm{dl}$ ), were investigated in the entire study population.

The estimations of serum CaT and CaI were done by colorimetric method [17]. The estimation of $\mathrm{SPO}_{4}$ was done by direct method [18]. Serum ALP was done by means of kinetic enzymatic method [19]. Serum creatinine estimation was done by Jaffe's method [20]. Albumin measurement was done by bromocresol green method [21]. The estimation of blood urea was done by diacetyl monoxime method [22]. Serum magnesium was estimated by colorimetric method [23]. Uric acid estimation was also done by colorimetric method [24]. The institutional ethics committee had given the ethical clearance to this study. All procedures performed in studies involving human participants were in accordance with the ethical standards of the institutional and/or national research committee and with the 1964 Helsinki declaration and its later amendments or comparable ethical standards.

\section{Statistical analysis}

All the variables (age, T-score, CaT, CaI, SPO , ALP, urea, creatinine, albumin, $\mathrm{Mg}$, and uric acid) were expressed in mean, standard deviation. All the parameters were differentiated between Case I and Case II using an unpaired Student's t-test. The Pearson correlation coefficient was applied between the ALP and with other parameters (CaT, CaI, $\mathrm{SPO}_{4}$, and uric acid). $\mathrm{p}<0.05$ was considered statistically significant. The statistical software IBM SPSS (Statistical Package for Social Sciences) Version 20 (Chicago II, USA) was used for statistical analysis

\section{RESULTS}

The mean age of the study population was 59.90 (8.51) years, which was non-significant between Case I and Case II $(>0.05)$. T-score in this study population $(-2.37[0.74])$ was significantly different between the groups $(-2.86[0.69]$ vs. -1.88 [0.38]). The mean values of the CaT level and CaI level in aforesaid population were $8.96(0.94)$ and $4.48(0.47)$, respectively. The mean level of CaT and CaI was significantly lower in Case I compared to Case II. SPO in the study group was higher in Case I compared to Case II, which was nonsignificant $(>0.05)$. Serum magnesium in total population was significantly $(<0.05)$ different between the groups. Serum ALP in the study population was higher in Case I compared to Case II and the difference was significant $(<0.05)$. Serum concentration of urea $(>0.05)$ was non-significant while the concentration of albumin was significant $(<0.05)$ between the groups in these postmenopausal women (Fig. 1). Serum creatinine in this study was significantly different between Case I and Case II (Fig.2). The mean concentration of serum magnesium was significantly different between the groups (Fig. 3). Serum Uric acid in this study population was highly significant $(<0.001)$ between the groups (Fig. 4$)$, and the level was higher in osteoporosis women compared to women having osteopenia (Table 1). Serum ALP was negatively correlated with CaT and CaI and positively correlated with $\mathrm{SPO}_{4}$ and uric acid. This association was significant $(<0.05)$ with $\mathrm{CaI}(-0.289)$, CaT $(-0.285), \mathrm{SPO}_{4}(0.371)$, and uric acid (0.305) (Table 2).

\section{DISCUSSION}

In postmenopausal women, osteoporosis occurs due to estrogen deficiency as well as an imbalance between bone resorption osteoclastic activity and bone formation osteoblastic activity [25].
Swaminathan stated that nutritional factors are essential and needs to be corrected in pathogenesis of osteoporosis in support to this study. They further concluded that in terms of diet, intake of calcium, magnesium, potassium, and vitamin $\mathrm{D}$ should be increased and intake of salt protein and phosphate should be reduced [26]. In this

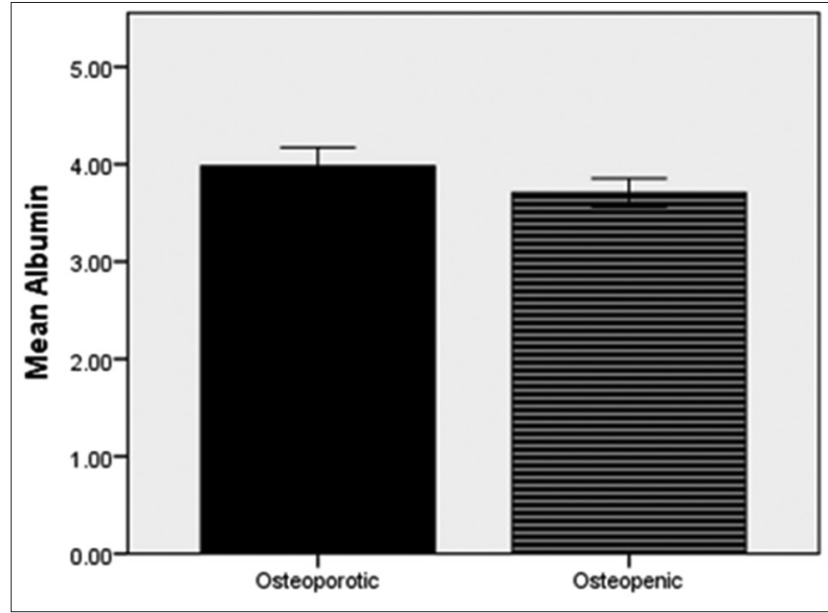

Fig. 1: Presentation of mean concentration of albumin between the groups

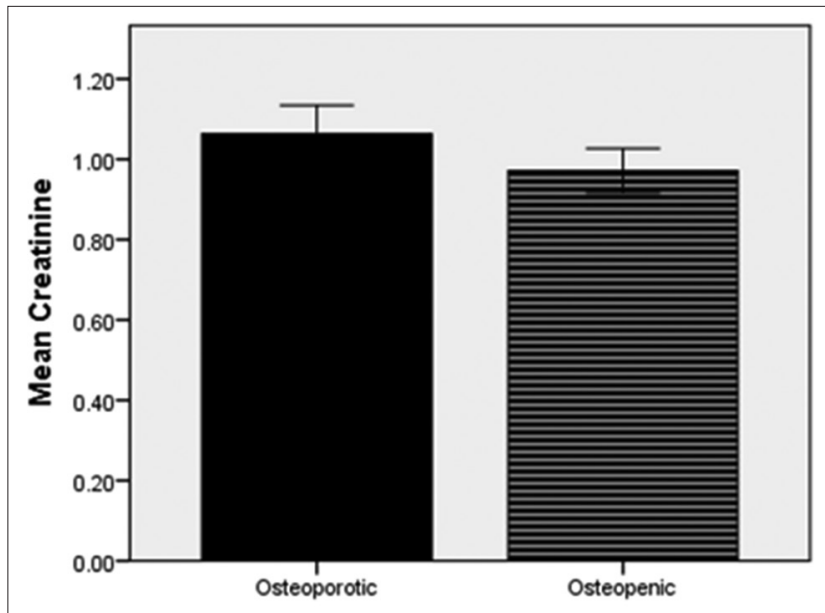

Fig. 2: Presentation of mean concentration of creatinine between the groups

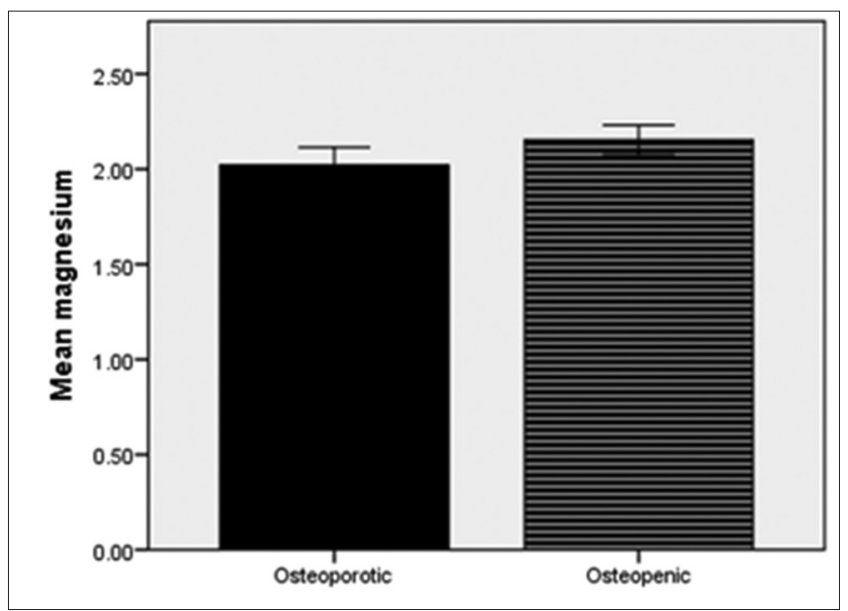

Fig. 3: Presentation of mean concentration of magnesium between the groups 
Table 1: Presentation of biochemical parameters between the groups

\begin{tabular}{|c|c|c|c|c|c|}
\hline \multirow[t]{2}{*}{ S. No. } & \multirow[t]{2}{*}{ Parameters } & \multirow{2}{*}{$\begin{array}{l}\text { Total }(70) \\
\text { Mean } \pm S D\end{array}$} & \multirow{2}{*}{$\begin{array}{l}\text { Case I (35) } \\
\text { Mean } \pm S D\end{array}$} & \multirow{2}{*}{$\begin{array}{l}\text { Case II (35) } \\
\text { Mean } \pm \text { SD }\end{array}$} & \multirow[t]{2}{*}{ p value } \\
\hline & & & & & \\
\hline 1 & Age (years) & $59.90 \pm 8.51$ & $62.08 \pm 10.22$ & $57.71 \pm 5.70$ & 0.031 \\
\hline 3 & Calcium total & $8.96 \pm 0.94$ & $8.66 \pm 1.06$ & $9.26 \pm 0.68$ & 0.007 \\
\hline 4 & Calcium ionized & $4.48 \pm 0.47$ & $4.33 \pm 0.53$ & $4.64 \pm 0.34$ & 0.006 \\
\hline 5 & $\mathrm{SPO}_{4}$ & $3.96 \pm 1.11$ & $4.16 \pm 1.21$ & $3.75 \pm 0.98$ & 0.127 \\
\hline 6 & $\mathrm{ALP}^{4}$ & $146.28 \pm 34.57$ & $155.31 \pm 39.03$ & $137.25 \pm 27.11$ & 0.028 \\
\hline 7 & Urea & $38.00 \pm 12.61$ & $39.34 \pm 13.02$ & $36.65 \pm 12.22$ & 0.377 \\
\hline 8 & Creatinine & $1.01 \pm 0.19$ & $1.06 \pm 0.20$ & $0.97 \pm 0.16$ & 0.044 \\
\hline 9 & Albumin & $3.84 \pm 0.51$ & $3.98 \pm 0.55$ & $3.70 \pm 0.42$ & 0.024 \\
\hline 10 & Magnesium & $2.08 \pm 0.25$ & $2.02 \pm 0.27$ & $2.15 \pm 0.22$ & 0.029 \\
\hline 11 & Uric acid & $5.42 \pm 1.44$ & $6.13 \pm 1.31$ & $4.71 \pm 1.21$ & 0.002 \\
\hline
\end{tabular}

Student's t-test between Case I and Case II. All the data were expressed in mean and SD. p $<0.05$ was considered statistically significant. SD: Standard deviation, ALP: Alkaline phosphatase

Table 2: A correlation between ALP and other parameters

\begin{tabular}{llll}
\hline S. No. & Parameters & R value & p value \\
\hline 1 & Total calcium & -0.285 & $<0.01$ \\
2 & CaI & -0.289 & $<0.01$ \\
3 & S. phosphate & 0.305 & $<0.01$ \\
4 & Uric acid & 0.371 & $<0.01$ \\
\hline \multicolumn{2}{l}{ By using Pearson correlation coefficient, $\mathrm{p}<0.01$ was considered statistically }
\end{tabular}
significant. ALP: Alkaline phosphatase

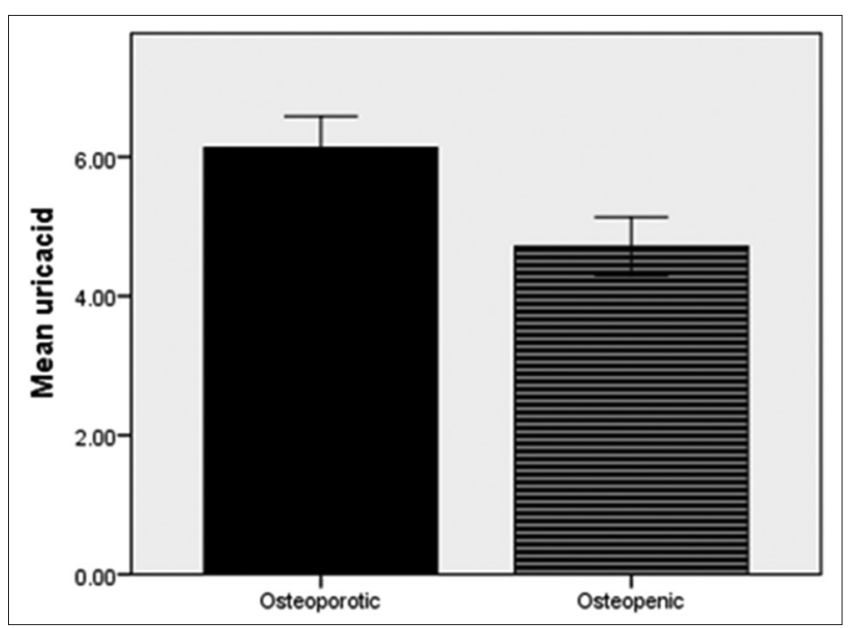

Fig. 4: Presentation of mean concentration of uric acid between the groups

study, serum calcium was significantly higher in osteopenia group compared to osteoporosis group similar to Roshan et al.'s study based on postmenopausal women [27]. $\mathrm{SPO}_{4}$ was higher in postmenopausal osteoporotic women compared to osteopenia group. The consistent lower concentration of magnesium, from osteopenia to osteoporosis in postmenopausal women, was supported by Sharma et al. [28]. Magnesium transport system could be affected in osteoporotic patients due to the presence of lower concentration of magnesium in red blood cells [29]. Mutlu et al. also supported these findings and concluded that trace elements supplementation may have beneficial effects on the bone mineral density [30]. Monitoring of serum creatinine could be helpful in the treatment of patients having low bone mineral density [31]. Liang et al. observed in postmenopausal women from the Chinese population that serum creatinine was higher in osteoporotic group compared to osteopenic group similar to this study. They observed negative correlation of serum creatinine with bone mineral density [32]. Klawansky et al. observed the significant renal complications in women having osteoporosis or osteopenia and it may increase with the age [33]. In an animal model-based study, osteoporotic rats were characterized by higher concentrations of serum creatinine and higher concentration of urea in support to this postmenopausal women-based study [34]. The Rancho Bernardo study supported this study as they did not find any significant difference in albumin concentration between the groups. They further summarized that the association between serum albumin and bone mineral density was not age dependent [35]. The serum albumin concentration in the whole population in this study was supported by Afshinnia et al.'s study [36]. The lower concentration of albumin in osteoporosis patients was supported by Nilsson et al.'s study [37]. Arpaci et al. also supported this study by observing higher concentration of albumin in osteopenic women compared to osteoporotic women [38]. ALP commonly used as bone mineral marker. It is a ubiquitous enzyme and plays an important role in osteoid formation and bone mineralization [39]. Jeon et al. observed the higher concentration of ALP in postmenopausal women. There was a higher concentration of ALP in osteoporotic women compared to osteopenia group [40]. Mukaiyama et al. supported these findings by concluding that higher bone turnover is a cause for increasing concentration of ALP [41]. The inverse correlation of ALP with serum calcium was supported by Bhattarai et al.'s study [42]. Fisher and Fisher observed a positive association of ALP with $\mathrm{SPO}_{4}$ in older patients with hip fracture in support to this study with similar findings [43]. The positive association between ALP and uric acid in this study was manifested in the postmenopausal women by Sharma et al.'s study [44]. In Korean man-based study, it was concluded that serum uric acid may act as a protective factor against the development of incident of osteoporotic fractures [45]. In postmenopausal women in this study, uric acid concentration was significantly higher in osteoporotic group compared to osteopenia. Oxidative stress has been found to be an important factor in pathogenesis of bone loss due to primary osteoporosis [46]. Experimental and epidemiological evidence suggested the beneficial effect of uric acid on bone metabolism as an antioxidant in postmenopausal women [47]. Lin et al. concluded that uric acid is associated with bone mineral density and has a strong protective effect at least osteopenia and osteoporosis [48].

\section{CONCLUSIONS}

In summary, the outcome of this study reveals the altered concentrations of various factors, which cannot be neglected while treating the patients having osteoporosis as well as osteopenia, especially in elder population. A significant result of serum creatinine highlighted the future prospects of developing renal impairment in osteoporotic patients, so monitoring is required. The increased concentration of uric acid may develop in the form of gout if not considered. Although the sample size of this study was small, large population-based study should be conducted to justify the fact. 


\section{REFERENCES}

1. Rossini M, Adami G, Adami S, Viapiana O, Gatti D. Safety issues and adverse reactions with osteoporosis management. Expert Opin Drug Saf 2016;15(3):321-32.

2. Inderjeeth CA, Poland KE. Management of osteoporosis in older people. J Pharm Pract Res 2010;40:229-34

3. Recker RR, Hinders S, Davies KM, Heaney RP, Stegman MR, Lappe JM, et al. Correcting calcium nutritional deficiency prevents spine fractures in elderly women. J Bone Miner Res 1996;11(12):1961-6.

4. Bikle DD. Vitamin D and bone. Curr Osteoporos Rep 2012;10(2):151-9.

5. Kanis JA, McCloskey EV, Johansson H, Cooper C, Rizzoli R, Reginster JY; Scientific Advisory Board of the European Society for Clinical and Economic Aspects of Osteoporosis and Osteoarthritis (ESCEO) and the Committee of Scientific Advisors of the International Osteoporosis Foundation (IOF). European guidance for the diagnosis and management of osteoporosis in postmenopausal women. Osteoporos Int 2013;24(1):23-57.

6. Riggs BL. The mechanisms of estrogen regulation of bone resorption. J Clin Invest 2000;106(10):1203-4.

7. Bonjour JP. Protein intake and bone health. Int J Vitam Nutr Res 2011;81(2-3):134-42.

8. Calvo MS, Eyre DR, Gundberg CM. Molecular basis and clinical application of biological markers of bone turnover. Endocr Rev 1996; 17:333-68.

9. Sissi C, Palumbo M. Effects of magnesium and related divalent metal ions in topoisomerase structure and function. Nucleic Acids Res 2009;37(3):702-11.

10. Jahnen-Dechent W, Ketteler M. Magnesium basics. Clin Kidney J 2012;5 Suppl 1:i3-14.

11. Rude RK, Kirchen ME, Gruber HE, Meyer MH, Luck JS, Crawford DL. Magnesium deficiency-induced osteoporosis in the rat: Uncoupling of bone formation and bone resorption. Magnes Res 1999;12(4):257-67.

12. Veronese N, Bolzetta F, De Rui M, Maggi S, Noale M, Zambon S, et al. Serum uric acid and incident osteoporotic fractures in old people: The PRO.V.A study. Bone 2015;79:183-9.

13. Nabipour I, Sambrook PN, Blyth FM, Janu MR, Waite LM, Naganathan V, et al. Serum uric acid is associated with bone health in older men: A cross-sectional population-based study. J Bone Miner Res 2011;26(5):955-64.

14. Malluche HH, Ritz E, Lange HP, Kutschera L, Hodgson M, Seiffert U, et al. Bone histology in incipient and advanced renal failure. Kidney Int 1976;9(4):355-62.

15. Kim KM, Lim JS, Kim KJ, Choi HS, Rhee Y, Oh HJ, et al. Dissimilarity of femur aging in men and women from a Nationwide Survey in Korea (KNHANES IV). J Bone Miner Metab 2013;31(2):144-52.

16. National Osteoporosis Foundation. Available from: http://www.nof.org/ articles/743. [Last accessed on 2016 Sep 09].

17. Ripoll JP. Colorimetric determination of calcium in serum using methylthymol blue. Clin Chim Acta 1976;72(1):133-9.

18. Daly JA, Ertingshausen G. Direct method for determining inorganic phosphate in serum with the "CentrifiChem". Clin Chem 1972;18(3):263-5.

19. Moss DW. Alkaline phosphatase isoenzymes. Clin Chem 1982;28(10):2007-16.

20. Husdan H, Rapoport A. Estimation of creatinine by the Jaffe reaction. A comparison of three methods. Clin Chem 1968;14(3):222-38.

21. Doumas BT, Watson WA, Biggs HG. Albumin standards and the measurement of serum albumin with bromcresol green. Clin Chim Acta 1971;31(1):87-96.

22. Momose T, Ohkura Y, Tomita J. Determination of urea in blood and urine with diacetyl monoxime-glucuronolactone reagent. Clin Chem 1965;11:113-21.

23. Smith AJ. A colorimetric method for the estimation of serum magnesium. Biochem J 1955;60(3):522-7.

24. Buchanan MJ, Isdale IC, Rose BS. Serum uric acid estimation chemical and enzymatic methods compared. Ann Rheum Dis 1965;24:285-8.

25. Management of osteoporosis in postmenopausal women: Position statement of The North American Menopause Society. Menopause 2010;17(1):25-54

26. Swaminathan R. Nutritional factors in osteoporosis. Int J Clin Pract 1999;53(7):540-8.

27. Mahdavi-Roshan M, Ebrahimi M, Ebrahimi A. Copper, magnesium, zinc and calcium status in osteopenic and osteoporotic post-menopausal women. Clin Cases Miner Bone Metab 2015;12(1):18-21.

28. Sharma R, Sharma P, Kumar P, Gupta G. Role of magnesium in postmenopausal women with osteoporosis and osteopenia. Asian J Pharm Clin Res 2016;9(1):183-4

29. Odabasi E, Turan M, Aydin A, Akay C, Kutlu M. Magnesium, zinc, copper, manganese, and selenium levels in postmenopausal women with osteoporosis. Can magnesium play a key role in osteoporosis? Ann Acad Med Singapore 2008;37:564-7.

30. Mutlu M, Argun M, Kilic E, Saraymen R, Yazar S. Magnesium, zinc and copper status in osteoporotic, osteopenic and normal post-menopausal women. J Int Med Res 2007;35(5):692-5.

31. Huh JH, Choi SI, Lim JS, Chung CH, Shin JY, Lee MY. Lower serum creatinine is associated with low bone mineral density in subjects without overt nephropathy. PLoS One 2015;10:e0133062.

32. Liang DK, Bai XJ, Wu B, Han LL, Wang XN, Yang J, et al. Associations between bone mineral density and subclinical atherosclerosis: A cross sectional study of a Chinese population. J Clin Endocrinol Metab 2014;99:469-77.

33. Klawansky S, Komaroff E, Cavanaugh PF Jr, Mitchell DY, Gordon MJ, Connelly JE, et al. Relationship between age, renal function and bone mineral density in the US population. Osteoporos Int 2003;14(7):5706.

34. El-Batran SA. Effect of combined and single hormonal therepy with testosterone and estrogen in experimentally induced osteoporosis in rats. J Egypt Soc Toxicol 2006;34:15-21.

35. Lunde AV, Barrett-Connor E, Morton DJ. Serum albumin and bone mineral density in healthy older men and women: The Rancho Bernardo Study. Osteoporos Int 1998;8(6):547-51.

36. Afshinnia F, Wong KK, Sundaram B, Ackermann RJ, Pennathur S. Hypoalbuminemia and osteoporosis: Reappraisal of a controversy. J Clin Endocrinol Metab 2016;101:167-75.

37. Nilsson SE, Takkinen S, Tryding N, Evrin PE, Berg S, McClearn G, et al. Association of biochemical values with morbidity in the elderly: A population-based Swedish study of persons aged 82 or more years. Scand J Clin Lab Invest 2003;63(7-8):457-66.

38. Arpaci D, Saglam F, Cuhaci FN, Ozdemir D, Ersoy R, Cakir B. Serum testosterone does not affect bone mineral density in postmenopausal women. Arch Endocrinol Metab 2015;59(4):292-6.

39. Indumati V, Patil VS, Jailkhani R. Hospital based preliminary study on osteoporosis in postmenopausal women. Indian J Clin Biochem 2007;22(2):96-100.

40. Jeon YK, Lee JG, Kim SS, Kim BH, Kim SJ, Kim YK, et al. Association between bone mineral density and metabolic syndrome in pre-and postmenopausal women. Endocr J 2011;58(2):87-93.

41. Mukaiyama K, Kamimura M, Uchiyama S, Ikegami S, Nakamura Y, Kato H. Elevation of serum alkaline phosphatase (ALP) level in postmenopausal women is caused by high bone turnover. Aging Clin Exp Res 2015;27(4):413-8

42. Bhattarai T, Bhattacharya K, Chaudhuri P, Sengupta P. Correlation of common biochemical markers for bone turnover, serum calcium, and alkaline phosphatase in post-menopausal women. Malays J Med Sci 2014;21(1):58-61.

43. Fisher L, Fisher A. Associations between liver function, bone turnover biomarkers and adipokines in older patients with hip fracture. J Endocrinol Metab 2014;4:121-35.

44. Sharma P, Sharma R, Kumar P, Gupta G. Assessment of uric acid in postmenopausal osteoporotic women. Asian J Pharm Clin Res 2016;9(2):138-9

45. Kim BJ, Baek S, Ahn SH, Kim SH, Jo MW, Bae SJ, et al. Higher serum uric acid as a protective factor against incident osteoporotic fractures in Korean men: A longitudinal study using the National Claim Registry. Osteoporos Int 2014;25:1837-44

46. Lean JM, Davies JT, Fuller K, Jagger CJ, Kirstein B, Partington GA, et al. A crucial role for thiol antioxidants in estrogen-deficiency bone loss. J Clin Invest 2003;112(6):915-23.

47. Ahn SH, Lee SH, Kim BJ, Lim KH, Bae SJ, Kim EH, et al. Higher serum uric acid is associated with higher bone mass, lower bone turnover, and lower prevalence of vertebral fracture in healthy postmenopausal women. Osteoporos Int 2013;24(12):2961-70.

48. Lin X, Zhao C, Qin A, Hong D, Liu W, Huang K, et al. Association between serum uric acid and bone health in general population: A large and multicentre study. Oncotarget 2015;6(4):35395-403. 